\title{
CERCLAGE FOR TORSIONAL FRACTURES OF THE TIBIA
}

\author{
H. HABERNEK, G. WALCH, C. DENGG
}

From the Regional Hospital, Schwaz, Austria

\begin{abstract}
We report the technique and results of percutaneous cerclage used in treating 186 torsional fractures of the tibia, most of which were due to skiing accidents in young patients. It is recommended only for this type of fracture and has the advantages of simplicity, a low rate of complications and a relatively brief period in hospital.
\end{abstract}

The treatment of spiral tibial fractures by percutaneous cerclage (Goetze 1933) is controversial. The method has been criticised in relation to possible neurovascular lesions at operation, delayed healing, nonunion, and secondary malalignment due to inherent instability. Nevertheless, it is still used in many centres (Buhler 1974). Experimental work has shown that cerclage wires cause little impairment of periosteal circulation, provided that no very extensive exposure has been made (Eitel et al. 1976). To help resolve some of the uncertainty about the value of this treatment we have evaluated our results in 186 torsional fractures of the tibia.

\section{TECHNIQUE OF OPERATION}

Under general anaesthesia, the patient is placed supine on a fracture table and leg traction is applied as shown in Figure 1. The fracture is then reduced to an anatomical position by manipulation, proceeding proximally to distally and using a percutaneously introduced hook to replace any butterfly fragment. Under radiographic control, skin marks are made at the levels proposed for cerclage.

After sterile draping, stab incisions are made at the selected levels, one group just lateral to the anterior tibial crest and the other a little behind the medial border. The posteromedial incisions must be posterior to the palpated medial border or it may be difficult to guide the wire catcher close to the tibial cortex (Figs. 2 and 3). The guiding instrument, a hollow probe, is inserted anteriorly, passed close to the lateral cortex and pushed

H. Habernek, MD, Orthopaedic Surgeon

G. Walch, MD, Orthopaedic Surgeon

C. Dengg, MD, Orthopaedic Surgeon

Unfallabteilung des A.ö.KH Schwaz, A-6130 Schwaz, Tyrol, Austria.

Correspondence should be sent to Dr H. Habernek.

(C) 1989 British Editorial Society of Bone and Joint Surgery $0301-620 X / 89 / 2066 \$ 2.00$

J Bone Joint Surg [Br] 1989;71-B:311-3. through the interosseous membrane, which is easily felt A $0.9 \mathrm{~mm}$ stainless steel wire is then introduced through the probe and caught by the wire-catcher (Fig. 3b). All the wires are similarly placed, and then brought back across the subcutaneous tibia as shown in Figure 3c. Their ends are stretched and twisted with Goetze's

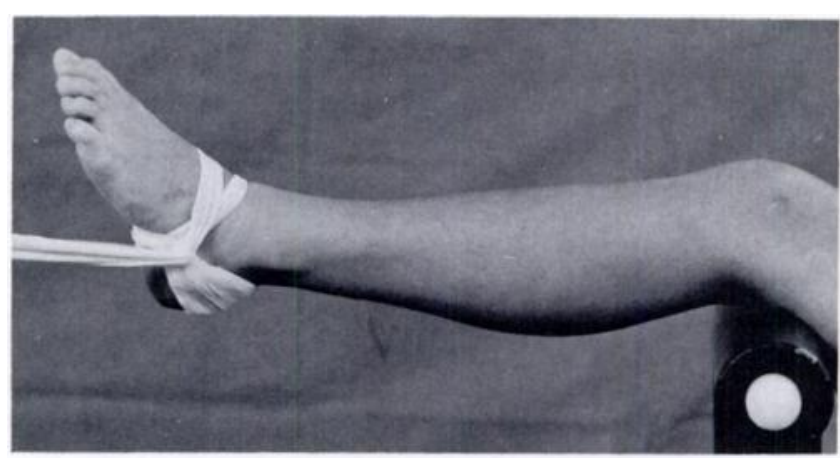

Fig. 1

Position of the leg on the fracture table, with traction applied via a sling.

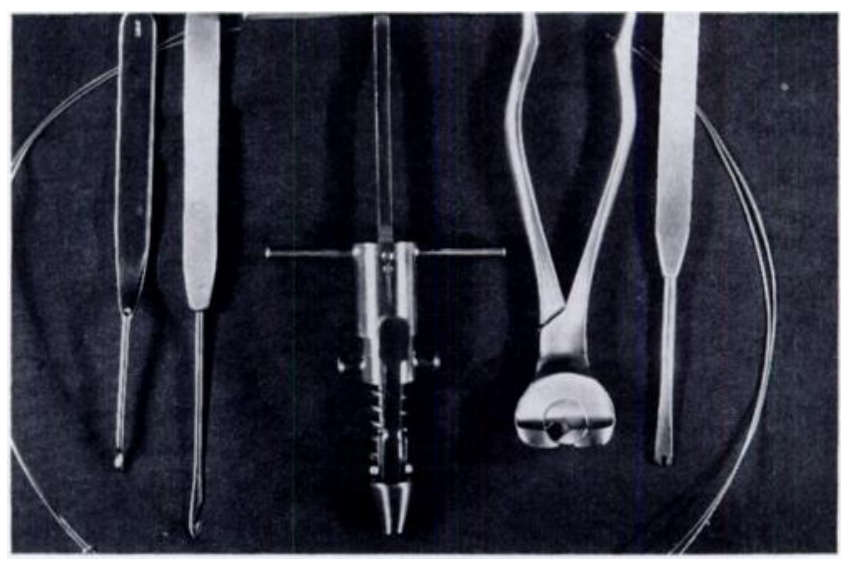

Fig. 2

Instruments used for wire cerclage. From left to right: hollow probe, wire catcher, Goetze wire tightener and twister, cutter and wire bender. 


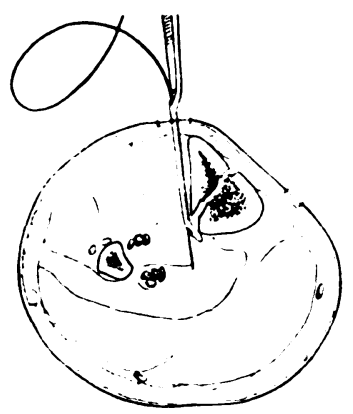

Fig. 3a

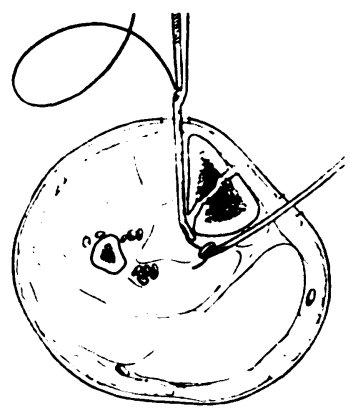

Fig. 3b

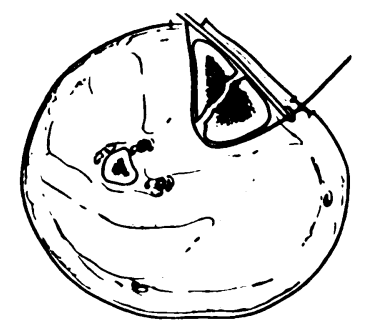

Fig. 3c
Diagrams to show the introduction of the hollow probe through an anterolateral stab wound and the method of passing the wire, catching it and completing the cerclage.

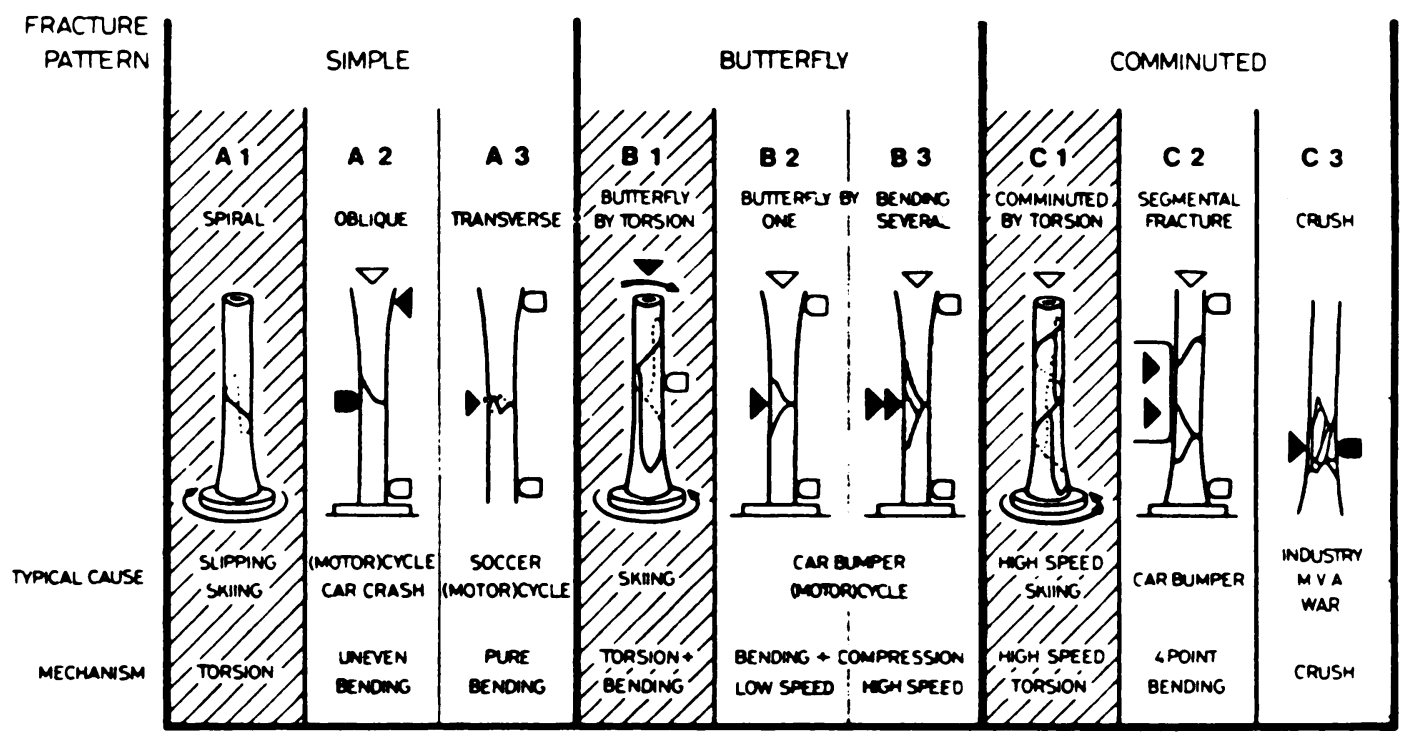

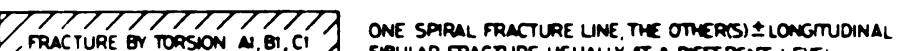
FRAC TURE BV TORSION N.BT. CI

Fig. 4

Johner and Wruhs classification of tibial fractures (from Clin Orthop 1983:178:7-25).
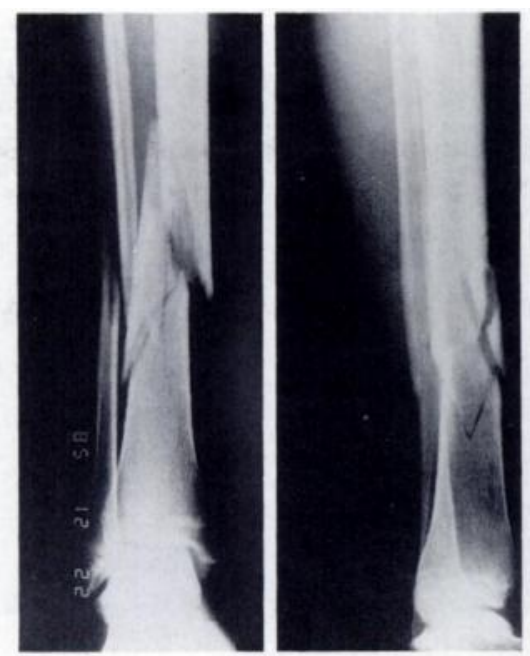

Fig. 5

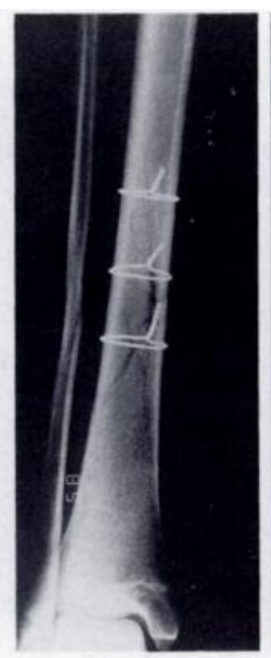

Fig. 6

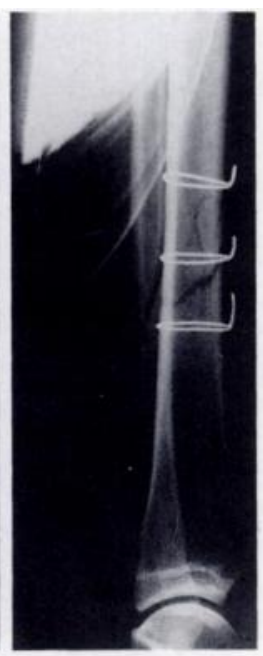

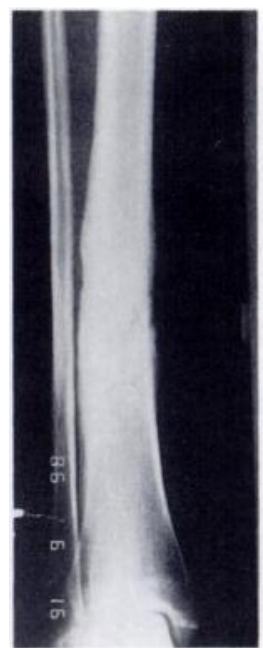

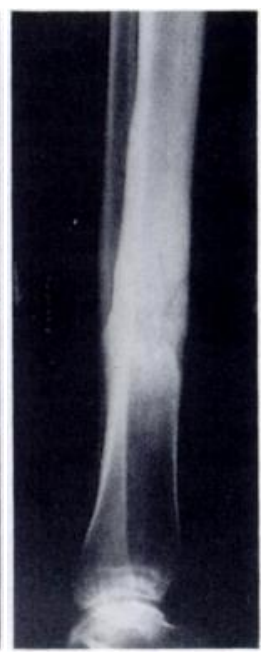

Fig. 7

A comminuted torsional fracture treated by percutaneous cerclage to give an excellent result. 
instrument under radiographic control. After releasing the traction, stability is tested and if satisfactory the wounds are closed. A split cast is applied and retained for 10 days, then replaced by a walking cast worn for about 12 weeks. The wires are normally removed through windows in the plaster at about six weeks.

\section{RESULTS}

Of the 423 lower leg fractures admitted to our unit between 1980 and 1985, 324 had operations and were reviewed personally or by questionnaire at a median follow-up of 3.5 years (one to six years). On the classification of Johner and Wruhs (1983) there were 209 torsional fractures (Fig. 4) and 186 of these, including five first-degree open fractures, had been treated by percutaneous cerclage.

There were 94 women and 92 men, of average ages 35 and 34 years respectively. Most had had skiing injuries $(74 \%$ of men, $81 \%$ of women), and the most common fracture was a torsion-bending lesion with one butterfly fragment $(\mathrm{B} 1,59 \%)$, while $22 \%$ had a simple spiral fracture (A1), and $11 \%$ a comminuted torsional fracture $(\mathrm{Cl}$, Figs. 5 to 7$)$. The most common level of injury was in the lower mid-shaft of the tibia $(27 \%)$.

There were 13 cases with secondary malalignment (all less than $10^{\circ}$ ) probably caused by too early weightbearing after 10 days in cases with less stable reductions. There were no instances of malrotation or shortening. Early complications included six superficial infections $(3.23 \%)$, which all healed within six weeks after drainage of any haematoma and parenteral antibiotics. Two of these infections were among the six patients with open fractures. Union was delayed in eight cases $(4.3 \%)$, in which a walking cast had to be re-applied for another three months. Four patients had deep vein thromboses $(2.15 \%)$, one with a pulmonary embolus $(0.54 \%)$, despite a prophylactic regime for all patients, using three doses of 5,000 i.u of heparin.

Three cases of refracture $(1.61 \%)$ were managed successfully by further cast immobilisation. Of five cases of peroneal palsy $(2.69 \%)$, due to pressure from a Braun splint, two recovered fully, and three had some residual sensory disturbance. There was one case of Sudek's atrophy and four patients developed minor degenerative changes in the ankle, though only one of them had any malalignment. There were no operative neurovascular lesions. Periods away from work varied from 11 to 21 weeks (mean 16 weeks) and return to sport was after 22 to 36 weeks (mean 28.4 weeks).

\section{DISCUSSION}

A quick, safe, inexpensive and easily taught procedure for the management of some tibial fractures is clearly of value and our results show that Goetze's cerclage method is satisfactory for the torsional type of fracture. It provides a percutaneous approach, avoiding extensive exposure and soft tissue injury. Cerclage interferes little with the blood supply of the bone providing the correct surgical techniques are used (Stöhrer et al. 1972; MacNab and de Haas 1974; Eitel et al. 1976); indeed it has been shown that vascularisation is increased after this type of osteosynthesis (Stöhrer et al. 1972; MacNab and de Haas 1974; Rhinelander 1974). In our series there was no case of nonunion and only eight cases where healing was delayed for up to six months. Conservative treatment by primary traction and subsequent cast fixation with early weight-bearing provides no better results, and may involve longer periods of bed-rest as well as a higher incidence of malalignment (Brown 1974; Sarmiento and Latta 1981; Böstmann 1986). Malalignment in our series was secondary, due to too early weight-bearing on comminuted fractures. If weight-bearing had been delayed in these cases normal alignment would probably have resulted.

This method should be used only for torsional fractures (A1, B1, and sometimes $\mathrm{Cl}$ ) in which the length of the fracture line exceeds twice the diameter of the tibia and full reduction has been achieved by manipulation under radiographic control. In these circumstances, cerclage, which uses simple instruments and involves only a short stay in hospital, can reduce the cost of health care.

No benefits in any form have been received or will be received from a commercial party related directly or indirectly to the subject of this article.

\section{REFERENCES}

Buhler J. Percutaneous cerclage of tibial fractures. Clin Orthop 1974:105:276-82.

Böstmann OM. Spiral fractures of the shaft of the tibia: initial displacement and stability of reduction. J Bone Joint Surg [Br] $1986 ; 68-B: 462-6$.

Brown PW. The early weight-bearing treatment of tibial shaft fractures. Clin Orthop 1974;105:167-78.

Eitel F, Dambe LT, Klapp F, et al. Vaskularisation der Diaphyse langer Röhrenknochen unter Cerclagen. Unfallheilkunde 1976:79:41-4.

Goetze O. Subcutane Drahtnaht bel Tibiaschrägfrakturen. Arch $f$ Klin Chir 1933:177:445-9.

Johner R, Wruhs O. Classification of tibial shaft fractures and correlation with results after rigid internal fixation. Clin Orthop 1983;178:7-25.

MacNab I, de Haas WG. The role of periosteal blood supply in the healing of fractures of the tibia. Clin Orthop 1974;105:27-33.

Rhinelander FW. Tibial blood supply in relation to fracture healing. Clin Orthop 1974:105:34-81.

Sarmiento A, Latta LL. Closed functional treatment of fractures. Berlin, etc: Springer-Verlag, 1981.

Stöhrer M, Preis G, Georgi P, Langhof J, Franke D. Untersuchungen über den Einfluss von Cerclagen auf die Durchblutungsverhältnisse am Hundeknochen. Langenbecks Arch Chir 1972:23-25. 